\title{
Knowledge and practice related to Occupational Hazards among Maruti Cement Factory workers in Mirchaiya, Siraha, Nepal
}

\author{
Jay Prakash Sah ${ }^{1 *, 6}$,Sanjeev Kumar Shah ${ }^{2}$, Dipendra Kumar Yadav ${ }^{1}$, Md Salahuddin ${ }^{3}$, Chandra Kant Yadav ${ }^{1}$, Md Sayfullah Razin ${ }^{4}$, \\ Mahjabin Rashid ${ }^{5}$ and Shalik Ram Dhital ${ }^{2}$ \\ ${ }^{1}$ Department of Medical Laboratory Science, School of Health and Allied Sciences, Pokhara University, Lekhnath -12 Kaski, Nepal \\ ${ }^{2}$ Department of Public Health, National Open College, Sanepa, Lalitpur, Nepal \\ ${ }^{3}$ Department of Physiology, Bangladesh Agricultural University, Mymensingh-2202, Bangladesh \\ ${ }^{4}$ College of Medicine, Shaheed Ziaur Rahman Medical College and Hospital, Bogra, University of Rajshahi, Bangladesh. \\ ${ }^{5}$ Honarary Medical Officer, Mymensingh Medical College Hospital, University of Dhaka, Bangladesh. \\ ${ }^{6}$ Soonchunhyang Institute of Medi-bio Science (SIMS), Soonchunhyang University, Asan-Si, Chunan, South Korea
}

Corresponding Author- Jay Prakash Sah, Assistant Professor, School of Health and Allied Sciences, Pokhara University, Lekhnath-12, Kaski Nepal, Phone No- +977-9841070420, 9846797774, Email- shahjayprakash1@gmail.com

\begin{abstract}
The main objective of the study is to find out the knowledge, practice and use of Personal Protective Equipments (PPE) among workers of cement factory limited located at Mirchaiya, Siraha, Nepal. We have tried to identify the various sources of information regarding occupational hazards, frequency of health visit in case of health problems or illness, hygiene practices among factory workers and sociodemographic characteristics like age, sex, marital status, income among the workers of cement factory. This is a descriptive cross-sectional study containing both qualitative and quantitative data. The primary data has been collected through semi-structured questionnaire assisted by researcher. Non-purposive sampling technique was used during the collection of data. Nearly three fourths of the respondents had satisfactory knowledge about occupational hazards. $86 \%$ workers responded as Tuberculosis to be the disease caused during work in cement factories. All the workers had some basic knowledge about PPE but only $33 \%$ of workers said that mask, gloves, boot and clothes fall under PPE. More than three fourths had knowledge regarding the effectiveness of the PPE. 96\% of the total respondents used PPE during their working time. About $31 \%$ workers had been suffering from illness. $72 \%$ workers had a trend to visit doctor only in case of illness or if required. Only $82 \%$ workers had a trend to wash eyes with water only in case of dust present in eye. Similarly, only $78 \%$ workers had a practice of hand washing with water. And, only $4 \%$ of the co-workers had information regarding occupational hazards and use of PPE. We conclude that the variables having significant influence on the knowledge and practice of workers about occupational hazards were education, receiving information about the job-associated hazards, and attending a training course about occupational health and safety. These variables should be taken into consideration in any program addressing occupational health and safety issues in Nepal.
\end{abstract}

Key Words: Occupational Health, Occupational Hazards, Personal Protective Equipment

(C) 2013 Microbes and Health. All rights reserved

\section{Introduction}

Occupational health is the study of promotion and maintenance of the highest degree of physical, mental and social well-being of workers in all occupations. The main focus in occupational health is to maintain worker's health and working capacity, to improve the working environment to become conducive to safety and health, and to develop the working organizations and cultures in a direction which supports health and safety of people (Ahmed et al., 2010).

Nowadays, industrialization in rapidly developing countries has been leading one of the threats for the people health and if industries are not well designed and appropriate safety measures are not adopted, serious adverse health consequences to the

workforce can be ensued. Shortage of manpower in some developing countries including Nepal, is met by employing expatriates primarily from less developed countries. The majority of these workers often described as economic migrants, have low levels of education and training. So many workers in the industrial sectors are exposed to significant occupational health hazards and consequently at high risk of work related diseases which vary from minor irritations or injuries to cancers (DeConinck, 2004; Steven, 2012). It has been found that 20,000 working people are being injured and 200 deaths occurs every year because of having occupational accidents within a formal sector industrial workforce of 0.4 million and total workforce of 11.2 millions. Generally causes of accidents can be mentioned due to unsafe working conditions, lack of supervision and training, use of old machinery and equipment, lack of sufficient maintenance, bad house-keeping practices, violation of safety rules, and overcrowded production units with very congested space (Nahyan, 1999; Merenu et al., 2007; Gautam and Prasain, 2011). A workplace injury can have a huge effect on worker's whole life. For the people working in a processing factory, some of their body parts mostly affected by injury are the hands, finger and thumbs. Wrist and shoulder injuries are also very common (Gautam and Prasain, 2011). Especially in case of cement factories, the population mostly exposed to cement dust pollution include workers and managers of cement plants and factories; families of workers and managers living in staff houses of factories; and other neighborhood habitations. Industrial development is undoubtedly the foundation of sustainable economic development as well as self dependent economy but 
work related accidents and diseases have been continuing to be serous problem in the world. Therefore, these realizing facts from the experience of developed countries, the government of Nepal has been also giving emphasis since the beginning of the democratic era (1950) though the history of modern industries development during Rana regime in 1936. The pace of industrialization was not satisfactory in the Panchayat period even though government had placed emphasis on it. However, democratic government after 1990 set up the formulation and implementation of several industrial friendly policies to attract industrial investment (domestic and foreign) units (Mwaiselage et al., 2006; Merenu et al., 2007). Due to such flexibility of Nepalese government, Industrialization is increasing gradually day by day to increase the economy of whole country. Central Bureau of Statistics (CBS), Nepal says that the total numbers of industrial units are 35,772 all over the country (Gautam and Prasain, 2011). And Maruti Cement Factory Limited is the largest cement factory in the country established with an investment worth Rs 2 billion. It holds the ISO 2001/14001 quality standard marks (Poopnajaf et al., 2010).

In the twenty-first century, millions of people are working daily in a dusty environment (Sultan, 2004). The major health problem in the cement industry is dust related, which is emitted from various parts of the production process such as the raw materia crusher, rotary kiln, cranes, mills, storage silos and packing sections (Gautam and Prasain, 2011). Air born dust levels have been recorded in the air of workplace of cement factories from less than 5 to more than $40 \mathrm{mg} / \mathrm{m}^{3}$. The aerodynamic diameter of the cement dust ranges from 0.05 to $20 \mathrm{~lm}$ that is enough to make a target for whole respiratory tract to be infected (Singh and Pandey, 2011). The exposure to cement dust, fume and gases have led to impairment of respiration and a prevalence of respiratory symptoms amongst workers culminating in what has been described as a "Cement factory lung disease" The severity of the impairment of respiratory function has been shown to depend on exposure up to sever years (Fanan-Ujoh et al., 2014). In the same way, cement dusts cause chronic obstructive lung disease, restrictive lung disease, pneumoconiosis, and carcinoma of the lungs, stomach and colon. Other studies have shown that cement dust may enter into the systemic circulation; thereby reach the essentially all the organs of body and affect the different tissues including heart, liver, spleen, bone, muscles and hairs; and ultimately affecting their micro-structure and physiological performance (Zeleke et al., 2010). So, we aimed to assess the level of knowledge and practice related to occupationa hazards among cement factory workers in Maruti cement factory limited, Nepal. And these findings will provide a clue to aware the government of developing countries like Nepal to improve the policy for occupational health and safety performance for the workers.

\section{Materials and Methods}

A cross sectional descriptive study design was applied to find out the occupational hazardous knowledge and practice among workers of Maruti Cement Factory Limited located at Mirchaiya, Siraha, Nepal in the duration of six months from $1^{\text {st }}$ July to $30^{\text {th }}$ December 2013. Non-probability purposive sampling technique was applied to select the sample for data collection. The people, who refused to participate in the study, was excluded from the study.

Sample size

The sample size for this study was determined by the formula $\mathrm{n}=\frac{\mathrm{Z}^{2} \mathrm{pq}}{\mathrm{d}^{2}}$

Where, $\mathrm{n}=$ Desired sample size, $\mathrm{z}=$ Standard normal deviate usually considered 1.96 at $95 \%$ confidence interval (CI), $\alpha=$ Level of statistical significance, $\mathrm{p}=$ the proportion of the target population taken as $7 \%(0.07)$ so $q=1-p=0.93, d=$ degree of accuracy desired usually set at $5 \%=0.05$, Hence, desired sample size $(\mathrm{n})=(1.96)^{2} \times 0.07 \times 0.93 /(0.05)^{2}=100$

\section{Conceptual Framework}

This study was conducted based on an ideal conceptual model as correlating independent and dependent variables. The independent variables were categorized as socio-demographic factor (age, sex, caste, religion, income, education, occupation, marital status), knowledge related variables (risk, law, cause of hazards, benefit of PPE, effect on health), practice related variable (types of safety measures, use of PPE, first involvement in an occupation) and source of information (Electronics and printing media, co-workers, trainers, peer group) where we measured as knowledge and practice towards occupational hazards.

\section{Method of data collection}

Data were collected by using structured and semi structured questionnaire for worker's consent and convenience. Questionnaire was translated into local language to make more flexible to collect specific and precise data.

\section{Data processing and analysis}

Statistical Package for Social Science (SPSS) program was used for data analysis, where mean and standard deviation were used for continuous data analysis and frequency table for categorized data analysis. Paired sample t-test along with association between the level of knowledge and practice were used for $p$-value analysis ( $p$-values $<0.05$ as significant)

\section{Data presentation and interpretation}

Data were presented in the form of tables and graphs. Descriptive statistics were presented with frequency tables. Association was illustrated with cross tables and test statistics were added in the foot notes of the tables. Bar and pie charts were generated to illustrate descriptive statistics.

\section{Data quality management}

The completed questionnaires were collected, checked for completeness, clarity of the information, and finally compiled.

\section{Ethical issues}

Informed consent was taken before interview from the director of Maruti Cement Factory Limited. Respondents had right to refuse and withdraw from the study at any time. Confidentiality of the respondents was maintained.

\section{Results}

This cross-sectional study was conducted to explore the level of knowledge and current practice related occupational hazards among Maruti cement factory workers, Mirchaiya, Nepal. Data were collected by questionnaire method on 100 cement factory workers and were analyzed by SPSS-13.

Socio-demographic, Socio-cultural and Socio-economic backgrounds

According to socio-demographic characteristics of the study sample, the age of the workers ranged from 17 to less than 52 years with a mean age of $34.07 \pm 8.849$ years.

\section{Figure1.Age Group}

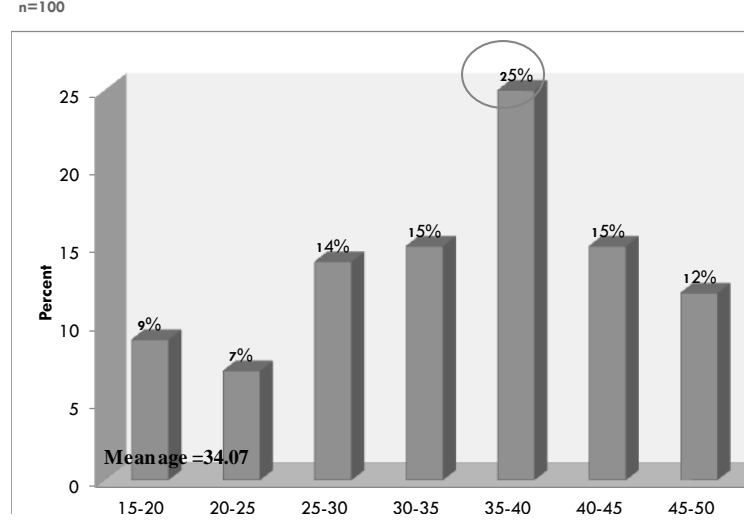




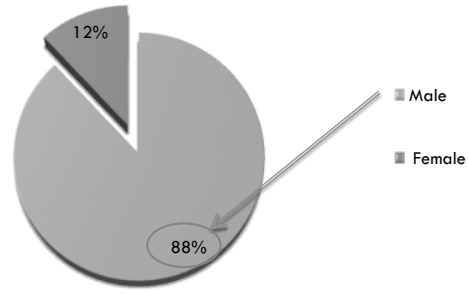

Figure 1: Distribution of workers by age group. The mean age of workers was $34.07 \pm 8.849$ years with age range of 17 to 52 years old. The data show that $25 \%$ workers were in the age group of 35-40 years followed by $15 \%$ of $30-35$ years, $14 \%$ of $40-45$ years, $12 \%$ of $25-30$ years, $15 \%$ of $45-50$ years $9 \%$ of $15-20$ years and least 3\% of 50-55 years old respectively. Figure 2: Distribution of workers by sex. Overall male workers were found to be dominant in comparison to female workers. Female workers were only $12 \%$.

Figure 3. Ethnicity Group

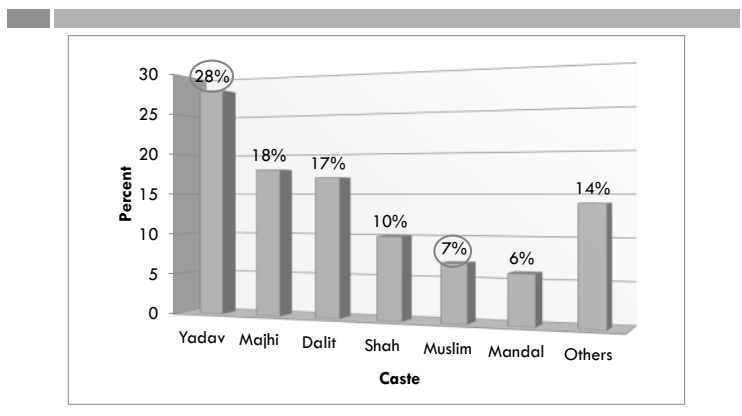

Figure 5. Education Status of Workers

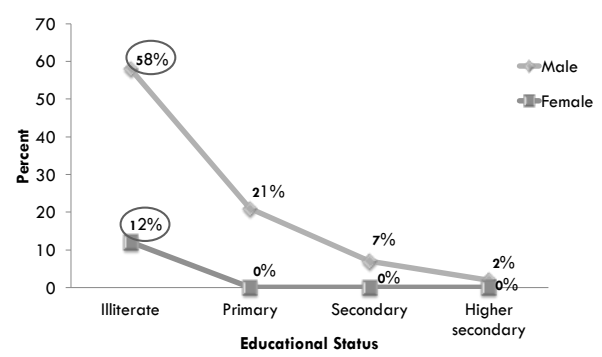

Figure 4. Religion

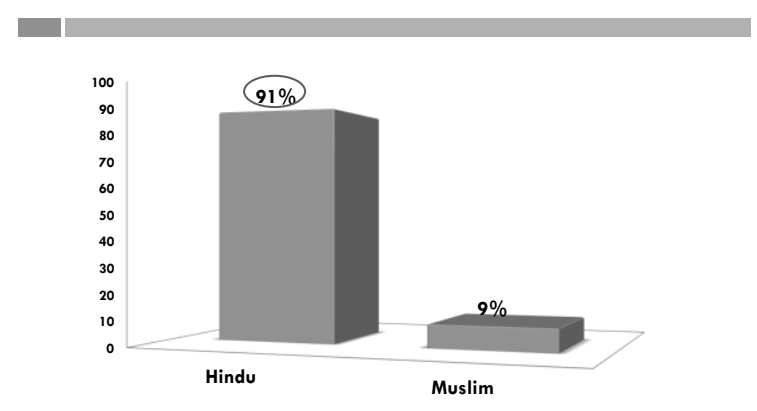

Figure 6. Family Size

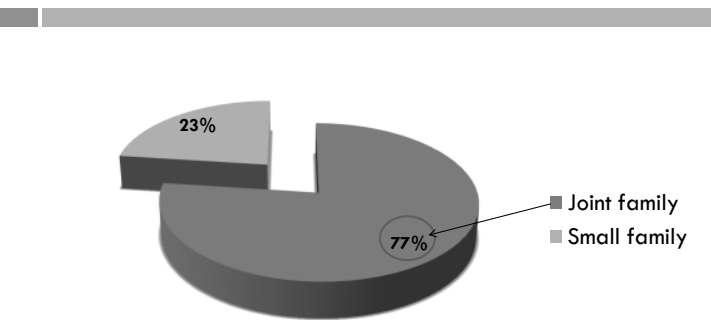

Figure 3: Distribution of workers by ethnicity group. This bar diagram shows that majority of workers were Yadav by $28 \%$ and people of other cast were gradually decreased by $18 \%$ Majhi, 17\% Dalit, 10\% Shah, 7\% Muslim, 6\% Mandal respectively. Figure 4: Distribution of workers by religion. Overall, Hindu people were dominant in the factory in comparison to Muslim. Only $9 \%$ Muslim were found to be involved in this occupation. Figure 5: Distribution of workers by educational status. All female workers were illiterate. In case of male, only $21 \%$ workers had primary level education. And most interesting thing was that only $2 \%$ workers had higher secondary level education. Figure 6: Distribution of workers by family size. The pie diagram shows that $77 \%$ workers were living in joint family and only $23 \%$ workers were with small family. 


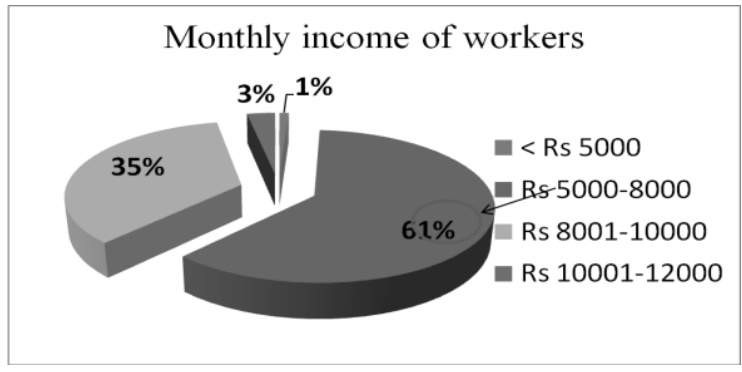

Figure 7: Distribution of workers by monthly household income. (Mean family income= NRs. 8000, 1US $\$=$ NRs. 93 (as per 2013 rate). The mean family income was NRs. 8000.86 having the range of NRs.4500 to NRs.12000. 61\% workers had monthly family income between NRs.5000-8000. Similarly, $31 \%$ had monthly income between NRs.8001-10000. And only 3\% workers had monthly income between NRs.10001-12000.

Knowledge of workers regarding occupational hazards This study has shown that most of the workers had general knowledge about effect of cement dust on their health.

Table 1: Distribution of workers by their knowledge about diseases caused by dust

\begin{tabular}{|l|c|c|}
\hline \multicolumn{1}{|c|}{ Diseases } & Frequency & Percentage (\%) \\
\hline Asthma & 11 & 11 \\
\hline Chest pain & 2 & 2 \\
\hline Common cold & 1 & 1 \\
\hline Fever, cough & 1 & 1 \\
\hline Gall stone & 7 & 7 \\
\hline Gastritis & 1 & 1 \\
\hline Headache & 1 & 1 \\
\hline Knee pain & 1 & 1 \\
\hline Lung disease & 3 & 3 \\
\hline Polio & 1 & 1 \\
\hline Rashes in chest & 1 & 1 \\
\hline Tuberculosis & 56 & 56 \\
\hline Do not know & 14 & 14 \\
\hline Total & 100 & 100 \\
\hline
\end{tabular}

Table 1 illustrates the distribution of workers by their knowledge about disease caused by cement dust. Overall, Most of the workers $(56 \%)$ had knowledge about Tuberculosis caused by cement dust. in the same way, only $11 \%$ workers said that it is the causative agent of Asthma. And only few workers had knowledge about other diseases are caused by cement dust.

Figure 8. Knowledge about cement can disease

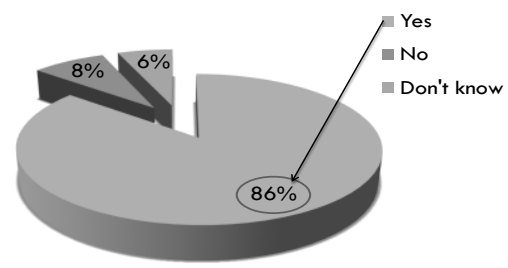

Figure 9. Knowledge About Factory Policies

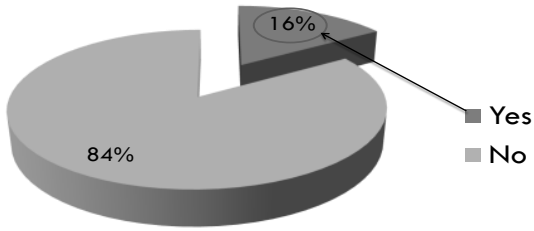

Fig 10. Knowledge about types of PPE

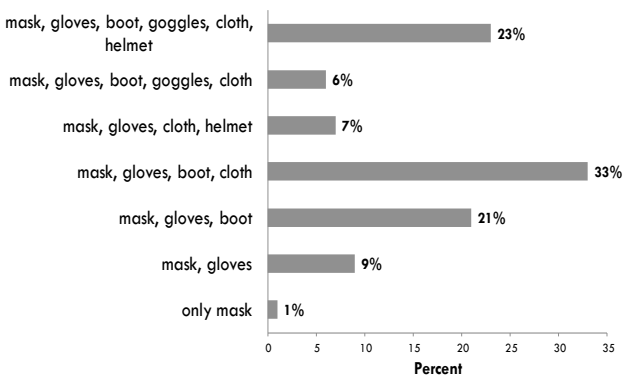

Fig 11.knowledge about benefit of PPE

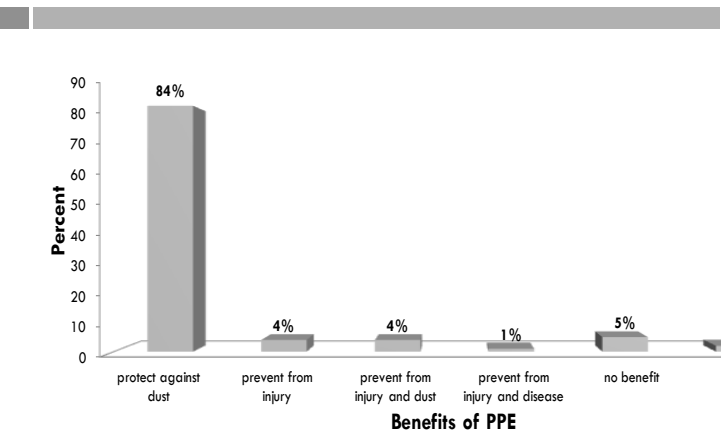

Figure 8: Distribution of workers by their knowledge about cement dust can cause disease. This pie diagram shows that majority of workers $(86 \%)$ had satisfactory knowledge regarding cement dust that can cause disease. And only $8 \%$ workers said that cement dust does not cause disease and rest $6 \%$ answered that they did not know its effect on their health. Figure 9: Distribution of workers by their knowledge about factory policies. Overall, most of the workers (84\%) had not knowledge about cement factory policies and $16 \%$ workers only knew about factory policies. Figure 10: Distribution of workers by their knowledge about types of PPE. This analysis shows that only $33 \%$ workers had knowledge about all types of PPE like mask, gloves, boot and protective clothes etc. And there was only $1 \%$ worker who had knowledge about mask only. Figure 11: Distribution of workers by their knowledge about benefit of PPE. This bar diagram shows that $84 \%$ workers had knowledge about protective role of PPE against dust. In general, only $2 \%$ workers had not any knowledge of benefit of PPE. And only $1 \%$ workers said that the PPE prevent from injury and disease.

Table 2: Distribution of workers by their knowledge about PPE

\begin{tabular}{|c|c|c|}
\hline $\begin{array}{c}\text { Knowledge about } \\
\text { PPE }\end{array}$ & Frequency & Percentage (\%) \\
\hline Yes & 100 & 100 \\
\hline
\end{tabular}

Table 2 revels the distribution of workers by their level of knowledge about PPE. This analysis shows that all workers had sharp knowledge about PPE. 


\section{Fig. 12 Use of PPE}

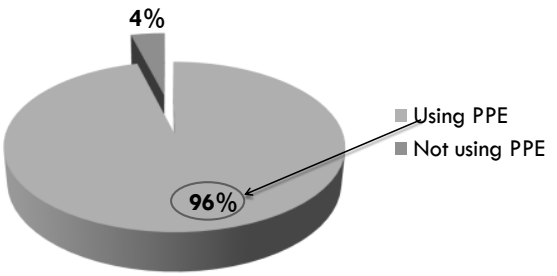

Fig. 13 Using PPE by Workers

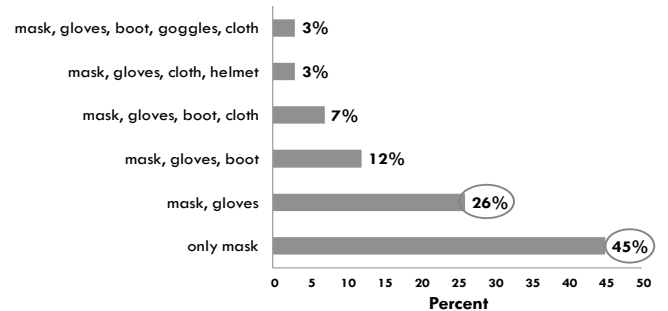

Figure 12: Distribution of workers by use of PPE. Over all, most of the workers had knowledge of PPE and so they were using PPE where as $4 \%$ workers were only unknown to benefit of PPE and they were not using PPE. Figure 13: Distribution of PPE used by workers.

This analysis shows that $3 \%$ workers were using mask, gloves, boot, goggles and protective clothes. In the same way, 3\% workers were using mask, gloves, protective clothes and helmet where as $7 \%$ workers were using mask, gloves, boot and protective cloth only. Similarly, $12 \%$ workers were using mask, gloves and boot where as $26 \%$ were using mask and gloves. And most of the workers (45\%) were using mask only.

\section{Fig. 14 Wearing practice of PPE}

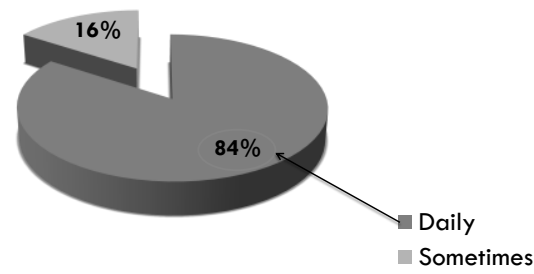

Fig. 15 Training received

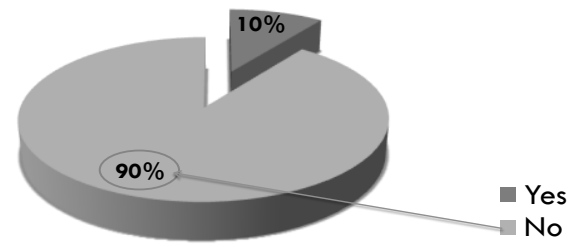

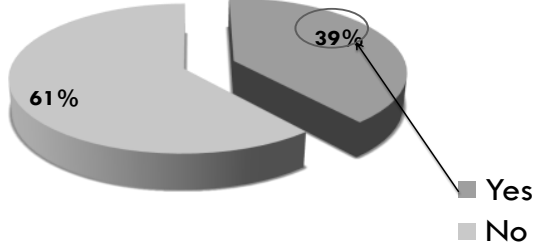

Fig. 17 Dust goes into eyes

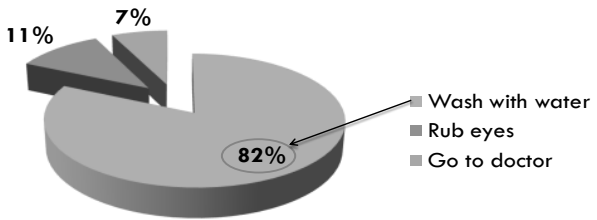

Figure 14: Distribution of workers by wearing practice of PPE. This analysis shows that most of workers $(84 \%)$ were wearing PPE daily where as $16 \%$ were wearing PPE occasionally. Figure 15: Distribution of workers having received training prior to join the job. Overall, most of the workers joined the factory without any previous training and only $10 \%$ workers had received training by their supervisor prior to join factory. Figure 16: Distribution of workers suffering from illness. This analysis shows that and $61 \%$ workers were healthy where as 39\% workers were suffering from illness. Figure 17: Distribution of workers having knowledge about precautions when dust goes into eyes. This pie diagram shows that washing of eyes with water by workers are common when any dust goes to their eyes where as some workers (7\%) are used to visit the doctor. One interesting thing is that $11 \%$ workers just rubs their eyes by finger.

Fig. 18 Hand washing practice

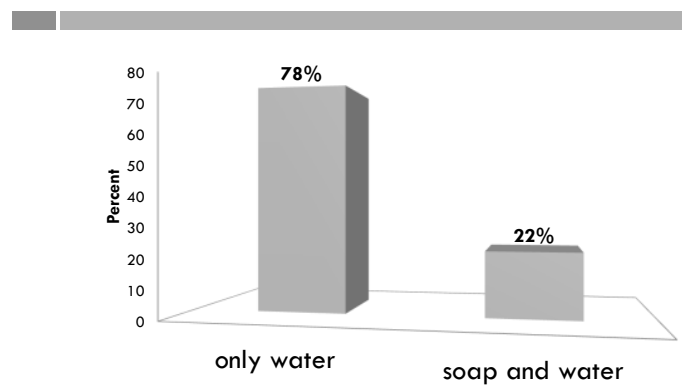

Fig. 19 Bathing practice after the work

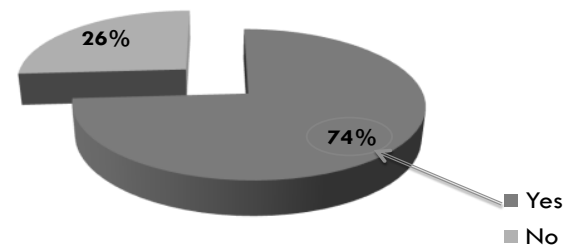




\section{Fig 20 Major incidents in factory}

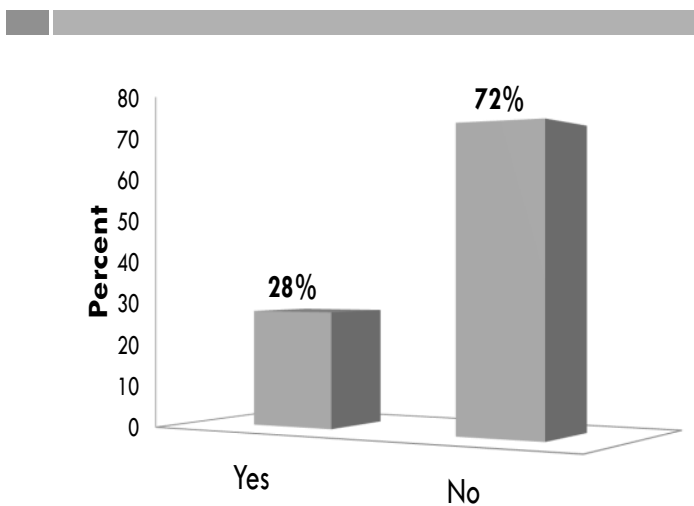

Fig. 21 Major incidents occurred in factory

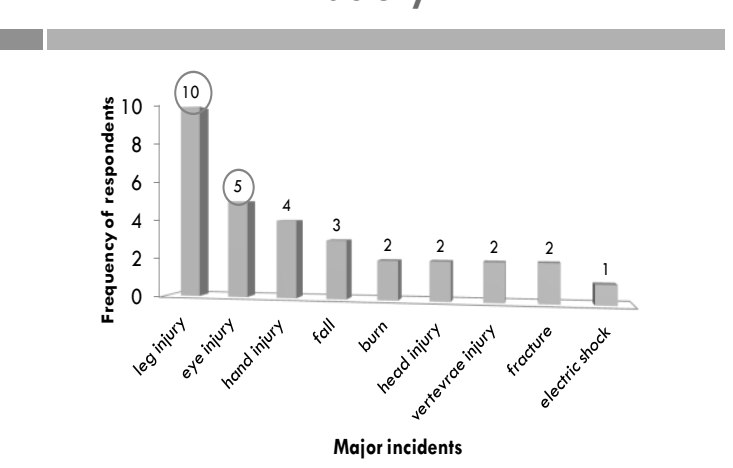

Figure 18: Distribution of workers having hand washing practice. This analysis shows that all workers use to wash their hands before taking meal. Among them, $78 \%$ workers use to wash their hand only by plain water where as $22 \%$ workers wash with soap and water. Figure 19: Distribution of workers having bathing practices. This analysis shows that majority of workers $(74 \%)$ regularly washed their body after returning from job and only $26 \%$ workers were found to be lazy who returned home and played with their children without prior bathing.

Figure 20: Distribution of major incidents in the factory. This analysis shows that $28 \%$ workers were agreed to this fact that improper prevention technique is the main cause of major accident whereas most of the workers(72\%) were disagreed to that fact. Figure 21: Distribution of major accidents occurred in factory. This analysis shows that majority of workers having major accidents were leg injury (10\%) followed by eye injury $(5 \%)$, hand injury $(4 \%)$, fell down $(3 \%)$, burn $(2 \%)$, head injury $(2 \%)$, vertebrae injury $(2 \%)$, leg fracture $(2 \%)$ and electric shock (1\%) respectively.

Information related sources regarding PPE and occupational hazards

We have taken co-workers, supervisor and peer group as the source of data to meet the demand of hypothesis to satisfy.

Table 3: Distribution of workers on the basis of source of information regarding occupation hazards and PPE

\begin{tabular}{|l|c|c|}
\hline $\begin{array}{c}\text { Information about PPE and } \\
\text { occupational hazards }\end{array}$ & Frequency & $\begin{array}{c}\text { Percent } \\
\text { \% }\end{array}$ \\
\hline Co-workers & 4 & 4 \\
\hline Supervisor & 91 & 91 \\
\hline Peer group & 5 & 5 \\
\hline Total & 100 & 100 \\
\hline
\end{tabular}

Table 4 illustrated the distribution of workers on the basis of source of information about PPE and occupational hazards. This analysis shows that mostly workers get information and knowledge about PPE and occupational hazards from their supervisor where as only $4 \%$ workers get such information from co-workers and $5 \%$ from peer group.

Association between level of knowledge and practice related to occupational hazards and PPE

Table 4: Relationship between knowledge about cement dust can cause diseases and practice of hand washing among cement factory workers

\begin{tabular}{|c|c|c|c|}
\hline Variables & Number & Correlation & $\begin{array}{c}\text { Sig. (2- } \\
\text { tailed) }\end{array}$ \\
\hline Fig 8 and Fig 19 & 100 & -0.109 & 0.778 \\
\hline
\end{tabular}

Table 4 reveals the relationship between knowledge and practices among cement factory workers. the table shows that satisfactory knowledge about disease causing effect of cement dust by most of the workers are not statically significant with washing habit of their hand with soap and water $(\mathrm{p}=0.778)$ (Figure 8, Figure 19).

Table 5: Relationship between knowledge and use PPE

\begin{tabular}{|c|c|c|c|}
\hline Variables & Number & Correlation & $\begin{array}{c}\text { Sig. (2- } \\
\text { tailed) }\end{array}$ \\
\hline Table 2 and Fig 13 & 100 & 0.00 & 0.045 \\
\hline
\end{tabular}

Table 5 shows the relationship between knowledge and use of PPE. The analysis shows that all workers had detail knowledge about PPE and so nearly all workers were using PPE. This relationship was found to be statistically significant $(\mathrm{p}=0.045)$ (Table 2, Figure 13).

Table 6: Relationship between education and knowledge about factory policies

\begin{tabular}{|c|c|c|c|}
\hline Variables & Number & Correlation & $\begin{array}{c}\text { Sig. (2- } \\
\text { tailed) }\end{array}$ \\
\hline Fig 5 and Fig 10 & 100 & -0.325 & 0.001 \\
\hline
\end{tabular}

Table 5 showing the relationship between education and knowledge about factory policies illustrates that illiteracy of workers are found to be statically significant with knowledge about factory policies $(\mathrm{p}=0.001)$ ( Figure 5 and Figure 10).

\section{Discussion}

The present cross-sectional quantitative study was conducted to explore the knowledge and practice related to occupational hazards among Maruti cement factory workers, Mirchaiya, Siraha Nepal. A questionnaire method with random sampling was applied to collect the data from Maruti cement factory workers having the age group of $17-52$ years. More than $70 \%$ workers were above 25 years of age (Table 1) and $88 \%$ of them were male. We also found that almost $91 \%$ workers were Hindu because of being their demographic distribution in Nepal (Figure 4). And rest of workers was Muslim. On the basis of ethnicity, almost one third of them were Yadav and least of workers were Muslim, Mandal and others (Figure 3). Our findings are approximately co-related with the findings obtained in Gautam and Prasain, (2011). In regard to the education status of factory workers, we found $12 \%$ female workers in this factory and all of them were illiterate, while in case of male workers, percentage of workers having education level as primary, secondary and higher secondary education were $21 \%, 12 \%, 2 \%$ respectively. In the same way, more than $90 \%$ of workers were married and $77 \%$ workers were staying with joint family (Figure 5). And the average family income was NRs.8000 (Figure 7) where as almost $61 \%$ workers had below average monthly family income. In this study we found very less people with below poverty line (daily income US $\$<1.25)$. 
As shown in Figure 8, 86\% workers had satisfactory knowledge regarding disease causing effect of cement dust and some workers $(6 \%)$ were unknown about the effect of cement dust. In the same way, the most of the workers $(86 \%)$ know that cement dust can cause diseases like Asthma, Tuberculosis, Gall stone, Lung disease, Chest pain and others (like Common cold, Fever, Cough, Gastritis, Headache, Knee pain, Polio, Rashes in chest, Cancer). These findings are nearly similar with the finding obtained by Singh and Pandey, (2011). Similarly, regarding their knowledge about factory policies, $84 \%$ workers did not have knowledge about the factory policies but most of them were familiar with effectiveness and protective role of PPE but still its use was rare. And their major sources of information about PPE and occupational hazards were their supervisor. These supervisors used to give these knowledge timely. Some workers $(10 \%)$ had some skill about how to use machines and PPE due to previously attended training and remaining $90 \%$ had not.

We also found that $61 \%$ workers did not have any illness and $39 \%$ workers had illness of abdominal pain, cough and cold, asthma, back pain, chest pain, dryness in throat, gastritis headache, TB, ulcer in mouth and stomach, almost $10 \%$ workers had Gastritis. About 47\% workers were getting ill 3-6 months interval and visit to health service if required. This finding was nearly significantly correlated with Poopnajaf et al., (2010). Similarly, we found that about $82 \%$ workers just wash their eyes by water when dust goes into their eyes and $11 \%$ workers were just rubbed their eyes in similar condition. And only $7 \%$ workers were visited to doctor appointed by factory. It is specially due to lack of knowledge about safety measure and occupational hazards among factory workers.

Similarly, all workers washed their hand before taking meal but majority of them washed with only plain water and only $22 \%$ workers washed their hand with soap and water. This is especially due to that they just want to clean their hand from dust but they do not have any idea about chemical effect of dust on health. In the same way, nearly $1 / 3$ part of workers did not wash their body after returning from duty to home. As a result of this habit, their family were become ill along with them. We also found that $1 / 4$ part of major accidents occurred in the factory due to improper prevention technique was leg injury.

\section{Conclusion}

Most of the cement workers do not know the effect of their exposure to the dust, fumes, gases which are serious artifacts to their health to cause serious problem in the body. In spite of having knowledge about the adverse health effects, physical hygiene, social hygiene, and benefit of PPE among workers; use of these skills are poor in their daily life. So we conclude that the variables having significant influence on the knowledge and practice of workers about occupational hazards are education, receiving information about the job-associated hazards, anc attending a training course about occupational health and safety. These variables should be taken into consideration in any program addressing occupational health and safety issues.

\section{Acknowledgement}

Our sincere, deepest and heartfelt gratitude goes to Managing Director and all the entire staffs of Maruti Cement Factory, Mirchaiya whose valuable contribution made our dream to fulfill. We would also like to express sincere thanks to Mr. Nirmal Shrestha, Mr. Chiranjeebi Shah and Mr. Murari Ghimire for their suggestions in every aspect of research works. Our sincere gratitude also goes to Mr. Shailesh Regmi, Mr. Koshish Raj Gautam and Mrs. Renu Yadav for supporting me in period of research.

\section{References}

Ahmed HO, S Mark and S Newson, 2010. Knowledge and practices related to occupational hazards among cement workers in United Arab Emirates. J Egypt Public Health Association, 85(3-4): 149-67.

De-Coninck JM, 2004. Occupational health and safety risks in the healthcare sector- Guide to prevention and good practice. European Agency for safety and Health at work, 5: 186-202.

Steven J, 2012. Occupational health and safety problems among workers in the wood processing industries in Mutare, Zimbabwe. Journal of Emerging Trends in Economics and Management Sciences (JETEMS), 3(3): 278-285.

Gautam RP and JN Prasain, 2011. Current situation of occupational safety and health in Nepal (a study report). General Federation Nepalese Trade Unions (GEFONT), Kathmandu, GEFONT Publication Kathmandu Nepal, 120: $1-83$.

Nahyan ZBSA, 1999. Federal law No (24) of 1999 for the protection and development of the environment. The Federal Environmental Agency, 340: 1-27.

Mwaiselage J, B Moen, M Bratveit M, 2006. Acute respiratory health effects among cement factory workers in Tanzania: an evaluation of a simple health surveillance tool. International Arch Occupational Environment Health, 79: 49-56.

Merenu I.A, FBO Mojiminiyi, CH Njoku and MTO Ibrahim, 2007. The effect of chronic cement dust exposure on lung function of cement factory workers in Sokoto, Nigeria. African Journal of Biomedical Research, 10:139-143.

Quiros L and AG Webb, 2005. Assessment of Cement dust concentrations and noise levels in a Cement plant in Nicaraguan. Center for Occupational and Environmental health, Ministry of Health, Nicaragua, 9: 1-7.

Shafik SA and ASA El-Mohsen, 2012. Occupational health: Health promotion program to improve health workers in Tourah cement factory. Journal of American Science, 8(3): 486-496.

Poopnajaf A, H Kakooei, M Hossein, F Ferasati and H Kakaei, 2010. The Effect of Cement Dust on the Lung Function in a Cement Factory, Iran. International Journal of Occupational Hygiene, 2(2): 74-78

Singh VS and DN Pandey, 2011. Human health risk due to cement dust exposure policy-brief. Climate Change and CDM Cell Rajasthan State Pollution Control Board, Jaipur, India, 2: 1-18

Sultan A and Meo, 2004. Health hazards of cement dust. Saudi Medical Journal, 25(9): 1153-1159.

Ujoh F, TU Frederick, 2014. Appraisal of social and health impact of a cement plant at host communities in Yandev, Nigeria. Science Journal of Public Health, 2(4): 275-83.

Zeleke JK, BE Moen and M Bråtveit, 2010. Cement dust exposure and acute lung function: A cross shift study. BMC Pulmonary Medicine, 1471(2466): 1-8.

Monga V, LP Singh, A Bhardwaj and HP Singh, 2012. Respiratory Health in Brick Kiln workers. International Journal of Physical and Social Sciences, 2(4): 226-244.

Vivekananda B, H Stovel, G Giri, J Heller, P Yadav, M Yadav, SP Gautam, V Bhaddamanika, V Pannavati, L Briggs, D Crespo, R Suwal and A Coope, 2009. Negative Impact of Industrialization along Lumbini Road, Nepal. Lumbini Institutions, Lumbini Garden, Nepal, 11(20): 1-11. 
Musa O, J Bamidele, A Salaudeen, H Saromi and A Omi, 2012. Occupational hazard awareness and safety practices among cement factory workers at obajana, Kogi state, Nigeria. Elixir Bio-diversity, 47: 9013-9018.

Mounia T, C Rachid, and C Yahyia, 2012. Promoting a culture of health and safety at work in cement plants. International Journal Of Computational Engineering Research, 2(8): 318321.

Vaidya SN, 2011. Occupational safety and health situation in Nepal. Department of Labour and Employment Promotion, Kathmandu, Nepal, 5(4):37-51.

Sana S, GA Bhat and HM Balkhi, 2013. Health Risk Associated with workers of Cement factories. International journal of scientific and research publications, 3(5): 1-5.

Manjula R, R Praveena, R Rashmi, GH Clevin, AS Ghattargi and DH Dorle, 2013. Effects of occupational dust exposure on the health status of Portland cement factory workers. Int J Med Public Health, 3(3): 192-96.

Agrawal N and NK Jain, 2014. Identification of Occupational Diseases and Injuries among the Workers Engaged in Manual Material Handling of Cement Industry. International Journal on Emerging Technologies, 5(1): 78-81. 